\title{
Does Blast Medium Affect Heterotopic Ossification in a Blast-amputation Model?
}

\author{
David E. Jaffe MD, David Yoo MS, Jason Blevins BA, Gregory Gasbarro MS, \\ Tyler Hughes BA, Ebrahim Paryavi MD, MPH, Thao Nguyen MD, \\ William L. Fourney PhD, Vincent D. Pellegrini Jr MD
}

Received: 29 October 2014/ Accepted: 15 April 2015/Published online: 28 April 2015

(C) The Association of Bone and Joint Surgeons (B) 2015

\begin{abstract}
Background Heterotopic ossification (HO) develops after nearly $2 / 3$ of traumatic blast amputations in the contemporary battlefield. This phenomenon has potentially devastating consequences for servicemen and women and its pathophysiology warrants further investigation using a previously developed animal blast model.

Questions/purposes We asked, what is the (1) severity (quantity) and (2) type (location) of HO bone formation
\end{abstract}

The institution of one or more of the authors (DEJ, VDP) has received, during the study period, funding from the United States Department of Defense Congressionally Directed Medical Research Program (Washington, DC, USA). One of the authors certifies that he (VDP), or a member of his immediate family, has or may receive payments or benefits, during the study period, an amount of USD 100,000-USD 1,000,000, from the United States Department of Defense Congressionally Directed Medical Research Program (Washington, DC, USA), an amount of USD 100,000-USD 1,000,000 from DePuy Orthopaedics (Warsaw, IN, USA), and USD 100,000USD 1,000,000 from the Agency for Healthcare Research and Quality (Rockville, MD, USA).

All ICMJE Conflict of Interest Forms for authors and Clinical Orthopaedics and Related Research ${ }^{\circledR}$ editors and board members are on file with the publication and can be viewed on request.

Each author certifies that his or her institution approved the animal protocol for this investigation and that all investigations were conducted in conformity with ethical principles of research.

This work was performed at the Department of Orthopaedics, University of Maryland School of Medicine, Baltimore, MD, USA.

D. E. Jaffe, D. Yoo, J. Blevins, G. Gasbarro, T. Hughes,

E. Paryavi, T. Nguyen

Department of Orthopaedics, University of Maryland School of

Medicine, Baltimore, MD, USA

W. L. Fourney

Department of Mechanical Engineering, A. James Clark School of Engineering, University of Maryland at College Park,

College Park, MD, USA after a hindlimb blast amputation with two distinct blast media. We hypothesized that a more "war-relevant" blast medium could be a more accurate model and potentially intensify the development of HO.

Methods Using a Sprague-Dawley rat model, the pathophysiology of ectopic bone formation in a traumatic hindlimb blast amputation was evaluated. Twenty-four animals underwent blast amputations and closure based on a previously established experimental model. Half the amputations were subjected to blasted sand and the other $1 / 2$ to blasted water. Serial orthogonal radiography was performed on each animal until euthanasia at 24 weeks to track the development of HO. Heterotopic bone severity and type were assessed by three independent graders at each time using a novel grading scale to assess quantity and quality of $\mathrm{HO}$.

Results All animals had radiographic evidence of $\mathrm{HO}$ develop. No differences were observed in ectopic bone development between sand and water blasting regarding severity or type at any time. Animals that received water and sand blasting had moderate $\mathrm{HO}$ develop at 24 weeks (median, 2.0 and 2.5 weeks, respectively; range, 13 weeks; difference of medians, $0.5 ; \mathrm{p}=0.67$ ). At the time of euthanasia, 10 animals that were water blasted had Type 3 HO compared with 11 in the sand-blasted group $(\mathrm{p}=1.00)$.

V. D. Pellegrini Jr $(\bowtie)$

Department of Orthopaedics, Medical University of South Carolina, 96 Jonathan Lucas Street, CSB 708, Charleston, SC 29425, USA

e-mail: pellegvd@musc.edu 
Conclusions Our study showed a clear development of HO after hindlimb blast amputation in a Sprague-Dawley rat model; however, no difference was observed in $\mathrm{HO}$ development based on the type of blast media. This suggests it is the blast mechanism that induces ectopic bone development, regardless of the blasted medium. The grading scale we developed for our animal-model study provided a reliable means of assessing $\mathrm{HO}$ severity and type.

Clinical Relevance We anticipate that future investigations will elucidate similarities between service members' wartime extremity injuries and the animal model used in our study, and with focused future research this model may have beneficial therapeutic implications as the pathophysiology of $\mathrm{HO}$ development is further understood.

\section{Introduction}

Recent conflicts in Iraq and Afghanistan have resulted in large increases in combat-related amputations among service members. Advances in protective equipment and evacuation protocols have led to a lower mortality rate for those who have experienced limb-compromising events. Consequently, the prevalence of wounded service members surviving major battlefield injury has increased substantially, with more than $88 \%$ of reported events in the Iraq conflict being survivable [9]. In the Middle East, nearly $70 \%$ of injuries are isolated to the extremities, and $80 \%$ of injuries are caused by explosive devices, resulting in high rates of survivable combat-related amputations [5, 6, 15]. Having survived initial trauma and resulting limb amputation, service members face complications that can compromise return to productive civilian life, including the development of heterotopic ossification (HO) in the residual limb.

$\mathrm{HO}$ is the formation of mature, lamellar bone in nonosseous tissues. Abnormal growth results from a disturbance in regulation of normal skeletogenesis and frequently is encountered in other orthopaedic settings, including THA and elbow fracture $[1,3,11,20-22,24$, $25]$ and traumatic brain injury and spinal cord injury [4, 8]. Despite being documented as far back as the Civil War, few comprehensive reports on HO frequency in combat-related injuries exist $[7,18,19]$. Potter et al. [18, 19] examined rates of ectopic bone formation in cases of battlefield amputations and found a prevalence approaching nearly $2 / 3$ of veterans who had undergone amputation. Compared with nonblast mechanisms of injury, blast-caused amputations correlated with increased rates of $\mathrm{HO}(66 \%$ blast-caused versus $42 \%$ nonblast mechanism) [19]. Forsberg et al. [7] reported similarly high rates of ectopic bone in service members with blast- related amputations. High rates of $\mathrm{HO}$ are clinically important because ectopic bone growth can be devastating for the wounded service member. Complications related to heterotopic bone in residual limbs include pain, overlying skin and muscle breakdown, poor prosthetic fit and function, need for surgical revision, and delayed rehabilitation [18]. Current treatment options are restricted to surgical excision of the offending bone [17]. Investigation of the effects of blast trauma on the musculoskeletal system must be a priority to enhance the care of warwounded veterans.

A previously conducted pilot study established a survivable, reproducible model for development of heterotopic bone in a blast-injured rat without the use of exogenous growth factors [23]. This original pilot model created clean amputations via a jet of blasted water. Using this original model design, we sought to further understand the factors that influence the development of ectopic bone in the residual limb of a blast-injured rat. Specifically, we asked, what are the comparative differences in (1) severity (quantity) and (2) type (location) of ectopic bone growth after blast amputation of hindlimbs under two different blast conditions of sand and water? Blasting with sand may better represent the local wound contamination that results from such an injury to soldiers during battle and offer a more accurate injury model. The contamination and residual debris of a sand-blasted amputation might encourage an environment of increased inflammation and potential for increased heterotopic bone. Accordingly, we hypothesized that more ectopic bone would develop in hindlimbs subjected to blast amputation with sand than those amputated with a column of propelled water.

\section{Materials and Methods}

The study was conducted under a protocol approved by our Institutional Animal Care and Use Committee and was funded by the Department of Defense under the Congressionally Directed Medical Research Program. Twenty-four male Sprague-Dawley rats (12-14 weeks old) underwent hindlimb blast amputation and immediate surgical closure, with minimal débridement of charred skin edges to facilitate primary wound healing. Twelve animals underwent amputation via a column of blasted sand (commercially purchased, nonsterile, coarse sand), while the other 12 underwent blast amputation with propelled, nonsterilized water. After wound closure, postoperative AP and lateral radiographs of the residual limb were obtained as baseline images. The rats were maintained for 24 weeks, and serial orthogonal radiographs of the residual limb were obtained at 10 days and at 4, 8, 12, 16, 20, and 24 weeks. Euthanasia was planned for all animals at 24 weeks. 


\section{Blast Amputation Procedure and Monitoring}

Inhaled isoflurane anesthesia was induced and maintained. Buprenorphine $(0.05 \mathrm{mg} / \mathrm{kg})$ and enrofloxacin $(5 \mathrm{mg} / \mathrm{kg})$ were administered subcutaneously for preemptive analgesia and prophylactic antibacterial coverage, respectively. The left hindlimb was cleared of hair with a clipper and cleansed with chlorhexidine and $70 \%$ isopropyl alcohol. Maintaining deep inhalation anesthesia by nose cone, the rat was positioned prone on a 2 -inch-thick aluminum platform that featured a 2.5-inch hole at its center; the animal was tightly secured with industrial strength Velcro $^{\circledR}$ (Velcro USA Inc, Manchester, NH, USA) (Fig. 1). The selected limb was positioned across the hole and centered at the desired amputation level with the use of silk suture and duct tape. The platform was located above a 2 foot $\times 2$ foot $\times 2$ foot steel tank filled with tap water or commercially purchased wet sand. An explosive charge ( $0.75 \mathrm{~g}$ of pentaerythritol tetranitrate) was submerged below the surface of the water or sand at a calibrated distance to provide an equivalent force at the injury site, directly beneath the center of the hole in the platform. Because of differences in mass of the blasted media, the standoff distance was adjusted to result in equivalent force transmission through the selected extremity. These adjustments were made by using test blasts of standard lead pencils to mimic rat femora and then confirming with cadaveric

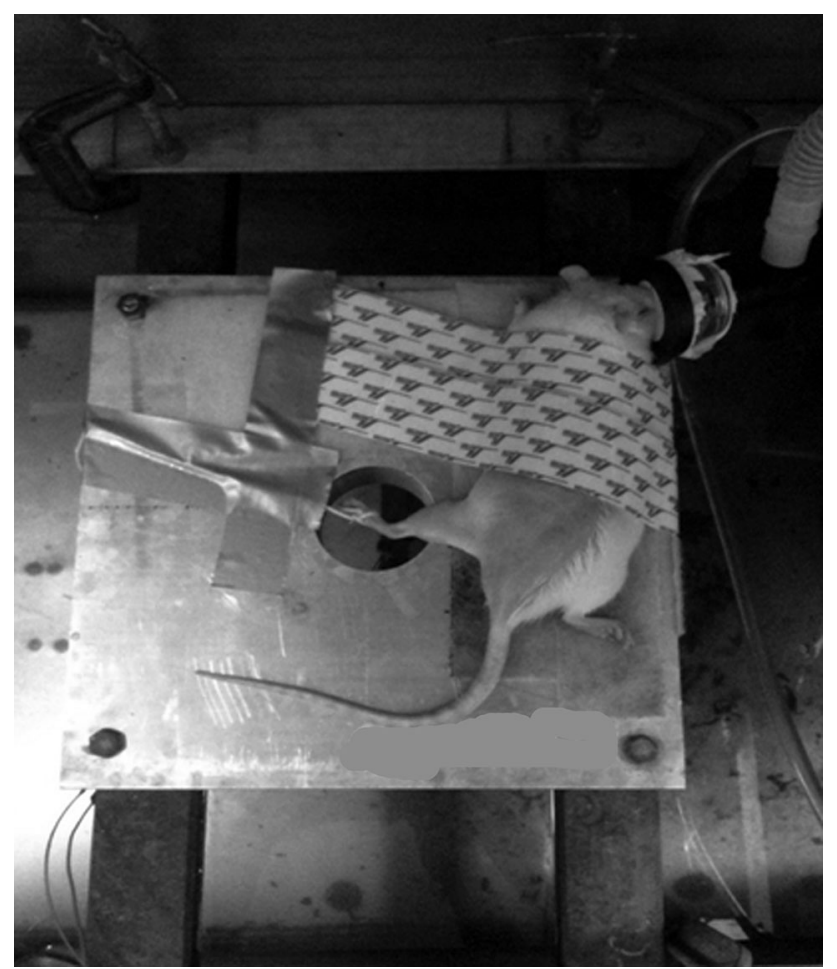

Fig. 1 The setup for blast amputation of the left hindlimb of a Sprague-Dawley rat is shown. specimens (standoff distance of 1 inch and depth of buried explosive of 0.5 inch for water blasts compared with 0 inch and 0.25 inch for sand blasts). The explosive was detonated with a commercially available detonation box (FS-10 firing system, Reynolds Industries Inc, Los Angeles, CA, USA). The resulting chemical reaction created a large volume of hot, high-pressured gases that acted against the surrounding medium, accelerating the blasted medium upward at velocities approaching four times the speed of sound in air (Mach 4). The high velocities were converted into pressure on impact with the plate and the animal's exposed extremity. Pressures on the order of tens of thousands of pounds per square inch were absorbed by the limb, which was quickly and cleanly amputated [12]. The protective platform effectively shielded the animals from injury to internal organs.

After amputation, the animals were maintained on inhaled isoflurane anesthesia and transferred to a nearby sterile operating table. Modest char was observed on the soft tissues, and minimal blood loss occurred because of cauterization of the vessels from the high temperature and pressure of the blast. The wound was irrigated with 150 to $250 \mathrm{~mL}$ of a 40:1 saline: chlorhexidine solution with a bulb syringe. Only prominent bone spikes underwent débridement. Damaged muscle was inverted without débridement to allow a primary fascial closure with a running 4-0 Vicryl $^{\circledR}$ suture (Ethicon; Novartis Animal Health US, Inc, Greensboro, NC, USA). The charred skin edges underwent sharp débridement to facilitate primary wound healing and were stapled and sealed with Histoacryl ${ }^{\circledR}$ tissue adhesive (B. Braun Corporation, Bethlehem, PA, USA). The animal was placed in a clean cage with warmed bedding and was monitored until awakening from anesthesia. Baseline orthogonal radiographs were obtained immediately after surgical closure (Fig. 2).

Animals received antibiotics (enrofloxacin, $5 \mathrm{mg} / \mathrm{kg}$ administered subcutaneously, twice daily) for 3 days per institutional guidelines. Analgesia was provided with buprenorphine, $0.05 \mathrm{mg} / \mathrm{kg}$ subcutaneously every 8 hours for 3 days and then every 12 hours for another 2 days after the procedure. Additional analgesia was available as indicated by physiologic signs of animal discomfort, but was not administered because the animals tolerated the procedure well.

\section{Animal Complications}

One hindlimb amputation in the water-blasted group underwent revision for tibial overgrowth of ectopic bone with puncture through the skin 4 weeks after injury. The revision included minimal shortening of the remaining tibia, gentle irrigation, and reclosure. No signs of gross infection were evident. The animal ultimately had severe HO (Type 

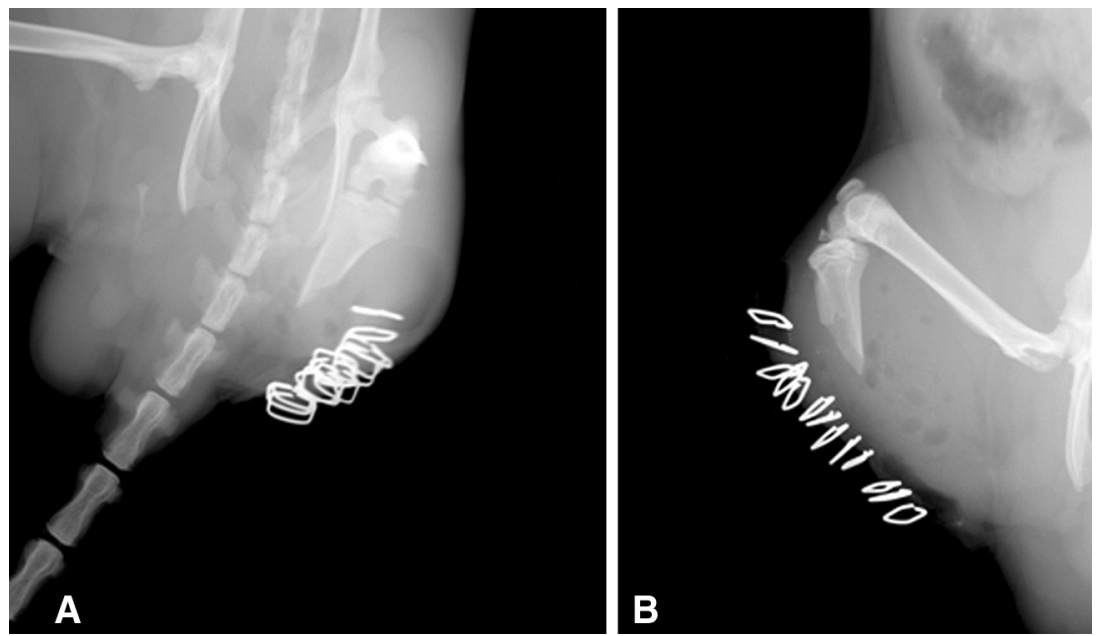

Fig. 2A-B (A) AP and (B) lateral view radiographs obtained immediately after blast of a residual hindlimb after blast amputation are shown.
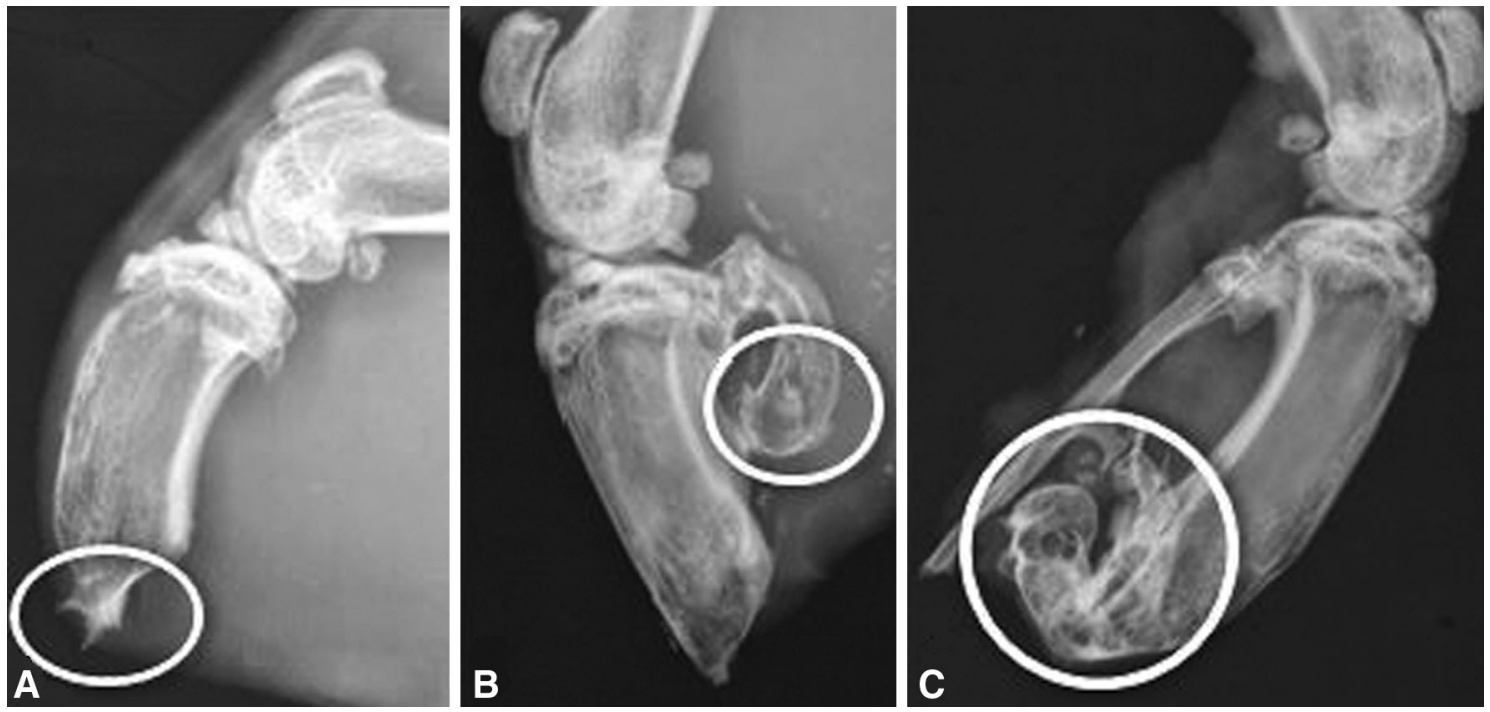

Fig. 3A-C The radiographs show examples of (A) mild, (B) moderate, and (C) severe heterotopic ossification in the hindlimbs of blast-injured rats.

3 , unanimously graded by all three graders [JB, DEJ, DY]) develop at 24 weeks. Three rats that had undergone sand blasting had postoperative wound infections develop that underwent irrigation, débridement, and immediate reclosure. Two of them had persistent infections and were euthanized at 9 weeks; both had severe Type 3 HO by the time of euthanasia (unanimously graded). The other infection resolved, and the animal was euthanized at 24 weeks with only mild Type 1 HO (unanimously graded). All other animals survived for the planned period of 24 weeks without reoperation or other complications. No statistically significant difference was observed in infection rate between blast amputations made with water and those made with sand ( 0 of 12 compared with three of 12 ; $\mathrm{p}=0.22$ ).

\section{Data Collection and Statistical Analysis}

After the animals were euthanized at 24 weeks, three independent graders (JB, DEJ, DY) reviewed the series of radiographs and assessed the severity of heterotopic bone as absent, mild, moderate, or severe based on a modification of the scale used by Potter et al. $[18,19]$ for human amputees. HO was considered to be mild if it measured less than $25 \%$ of the width of the tibial plateau on either the AP or lateral view radiograph, moderate if it measured $25 \%$ to $50 \%$, and severe if it measured more than 50\% (Fig. 3).

The ectopic bone was classified as one of three types. Type 1 was defined as bone growing contiguously with the residual limb while remaining in the normal bony configuration. Type 2 was defined as ectopic bone contiguous 

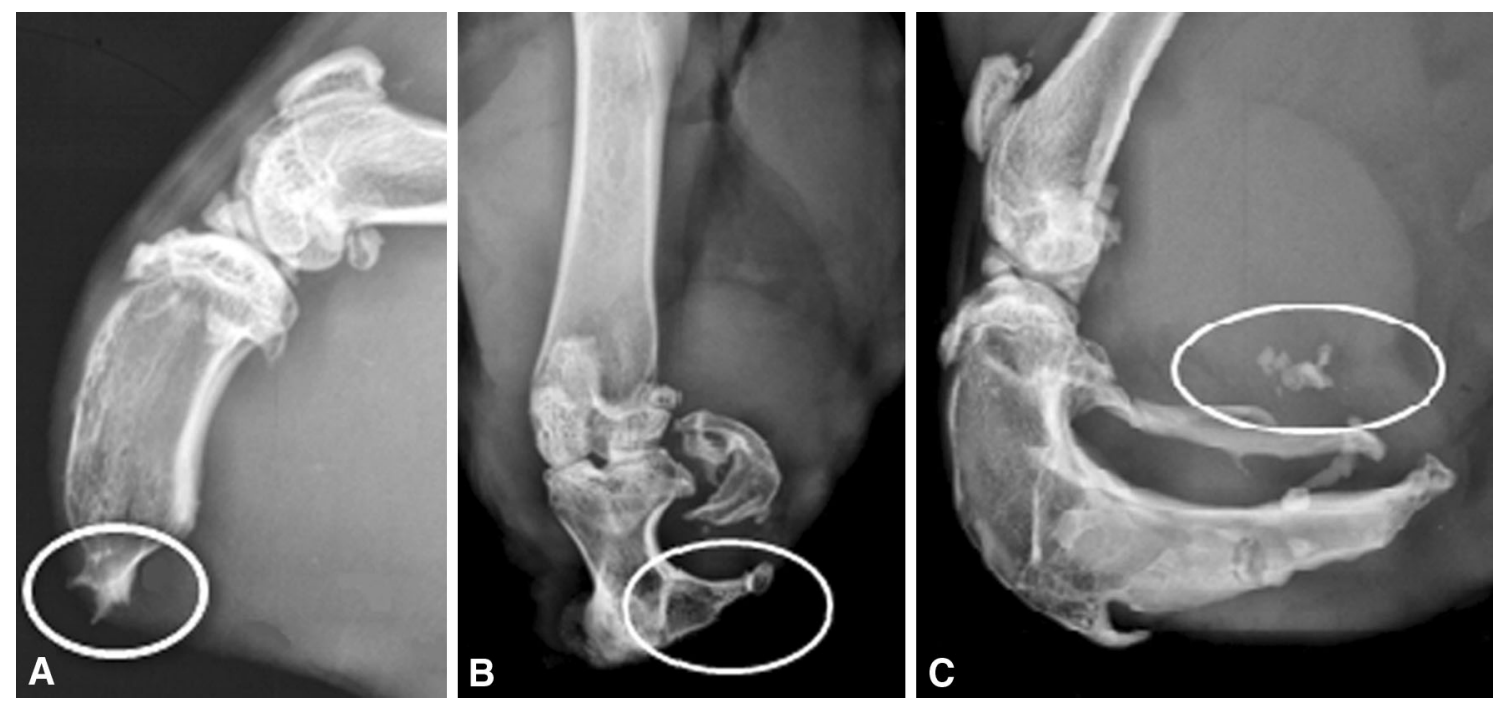

Fig. 4A-C The radiographs show examples of (A) Type 1, (B) Type 2, and (C) Type 3 heterotopic ossification in the hindlimbs of blast-injured rats.

with the residual limb skeleton but outside the normal bony envelope. Type 3 was defined as ectopic bone originating in the surrounding soft tissues of the residual limb-not contiguous with the residual bony anatomy (Fig. 4).

The three graders independently evaluated the radiographs of all 24 animals and assessed the severity and type of ectopic bone at three distinct times: 8,16 , and 24 weeks. The graders were blinded to blast medium. Each severity grade of $\mathrm{HO}$ was assigned a corresponding numerical value (absent $=0$, mild $=1$, moderate $=2$, severe $=3$ ). When reviewers disagreed, the score assigned with greatest frequency was used. Similarly, Type $3 \mathrm{HO}$ was declared if two of three graders identified a bony island.

Analysis of the data involved calculation of median HO severity and Mann-Whitney $U$ tests to determine significant differences in severity. To statistically analyze type, groups were dichotomized into presence or lack of Type 3 bony islands and were assessed with Fisher's exact test. Significance was assessed at an $\alpha$ level of 0.05 , and all $\mathrm{p}$ value calculations were two-sided.

The Cronbach $\alpha$ test was conducted to assess internal consistency among graders. For radiographic heterotopic bone severity, an overall $\alpha$ statistic of 0.93 indicated excellent internal consistency among three graders at all times evaluated. For type of heterotopic bone (Type 1, 2, or 3 ), the Cronbach $\alpha$ statistic was 0.78 (acceptable internal consistency).

\section{Results}

The severity of heterotopic bone formed in the blasted animals progressed with time in each experimental group.
At 8 weeks, animals that had been water blasted and sand blasted had a median severity of 1.0 (range, 1-3; difference of medians, $0 ; \mathrm{p}=0.56$ ). At 16 weeks, animals that had been water blasted had a median severity of 2.0 , compared with 1.5 in animals that had been sand blasted (range, 1-3; difference of medians, $0.5 ; \mathrm{p}=0.67$ ) (Fig. 5). Ultimately, at 24 weeks, animals that had been water blasted had median severity of 2.5 , compared with 2.0 in animals that had been sand blasted (range, 1-3; difference of medians, $0.5 ; \mathrm{p}=0.67)$. No difference was observed in $\mathrm{HO}$ severity at any time.

Bony islands were observed frequently before euthanasia at 24 weeks regardless of the medium used. At 8, 16, and 24 weeks, there were six, nine, and 10 animals that had been water-blasted that were noted to have Type 3 HO. In animals that were sand blasted, there were seven, 10, and 11 animals with Type $3 \mathrm{HO}$ at each respective time. No difference was observed in HO type at any time (six of 12 versus seven of $12, \mathrm{p}=1.00$; nine of 12 versus 10 of 12 , $\mathrm{p}=1.00$; and 10 of 12 versus 11 of $12, \mathrm{p}=1.00$ ).

\section{Discussion}

Between 2001 and 2005, more than 3500 extremity wounds were recorded in the Joint Theater Trauma Registry. The injuries to US service members were evenly distributed between upper and lower extremities, and $75 \%$ were the result of explosive munitions $[15,16]$. To further explore the phenomenon of ectopic bone formation occurring after blast amputation, we developed an animal model to replicate the process without addition of exogenous osteogenic agents. A previous study showed high survivability after 


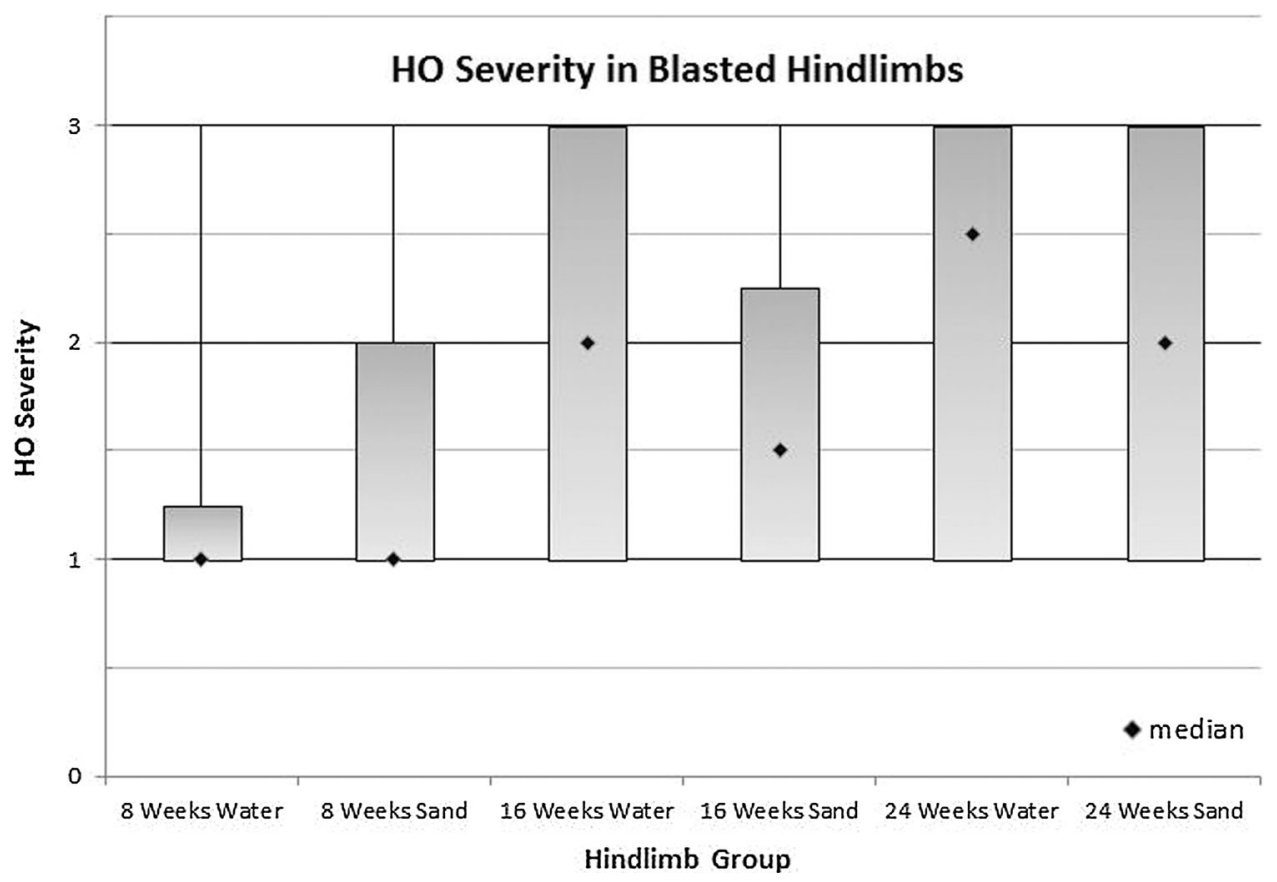

Fig. 5 The median heterotopic ossification severity of each group of rats at three different times is shown. A progressive increase in the observed severity of heterotopic ossification occurred with time until euthanasia at 24 weeks. A severity score of 1 corresponds to mild

controlled blast amputation of a single extremity in a Sprague-Dawley rat model [23]. In the current study, the model showed that the blasted medium had no effect on either the severity or type of heterotopic bone that developed, disproving our hypothesis that sand blasting would result in intensified ectopic bone growth.

The model has some limitations but it consistently creates ectopic bone in the blasted extremity. Although typical amputation management involves extensive débridement of damaged soft tissue, we chose to invert damaged tissue without significant debulking to allow for more experimental consistency. Currently, to our knowledge, no literature exists to validate our model as a representation of $\mathrm{HO}$ in humans. However, the model is a realistic model of blast injury endured by service members during combat. Although larger animals (ie, rabbit and sheep models) may be better representatives of human $\mathrm{HO}$ formation, previous traumatic models using larger animals have had limited success $[14,22,26,27]$. This model uses a realistic mechanism of injury and reliably induces heterotopic bone without exogenous growth factors. Current molecular and histologic studies are being conducted to validate this model as a true representation of the pathophysiology involved in human HO. With our severity scale and type classification, good consistency was noted among the graders. We identified some potential reasons for the disagreement that existed among reviewers. Regarding $\mathrm{HO}$ heterotopic ossification, whereas scores of 2 and 3 represent moderate and severe heterotopic ossification, respectively. The vertical lines depict the range of severity.

type, the rats' fibulae typically shattered into many pieces, making it difficult to ascertain whether bone in the surrounding soft tissue represented fragments retained from initial injury or newly formed islands of ectopic bone. This limitation was mitigated by obtaining radiographs immediately after the blast. Despite these potential limitations, our radiographic classification scheme was reliably consistent among graders and is suitable for use with future experiments.

No difference in severity of $\mathrm{HO}$ was observed among amputated sand-blasted extremities compared with amputated water-blasted extremities. Perhaps with more animals in each group, we might have seen a difference between the two groups; however, pilot work showed that 12 animals are sufficient to detect statistically significant differences in heterotopic bone severity. We expected higher rates of infection and wound complications in the sand-blasted group because of greater contamination with incomplete débridement. We hypothesized that this would result in increased ectopic bone development secondary to general amplification of a local inflammatory response. Muscle injury and inflammation are critical initiators of $\mathrm{HO}$ because they induce expression of BMP. Mesenchymal stem cells respond to local BMPs and are induced to differentiate into osteoblasts, leading to new bone formation. The paracrine action of BMPs might account for observed differences in ectopic bone formation after local injury [2, 
$10,13]$. Despite this proposed mechanism of muscle trauma initiating heterotopic bone, we did not see a significant difference between our two experimental groups. Because we calibrated the force imparted to the limb by adjusting the blast standoff distance, it may be true that the rats' immune systems were not significantly upregulated in the sand-blasted group compared with the water-blasted group. Future biomolecular study is required to determine the cellular initiation of HO in our model.

The results of this study showed that there was no difference in the rate of formation of ectopic bony islands between the two experimental groups. We hypothesized that we would see more bony islands develop in the hindlimb muscle that was injured with sand blasting because of increased contamination and a possible difference in microscopic trauma. As with comparing severity of $\mathrm{HO}$ that formed, this proved not to be the case. Perhaps this implies that a systemic response is the key initiator of $\mathrm{HO}$ rather than a purely local phenomenon. Future research will be directed at identifying local and systemic factors associated with the formation of bony islands in the soft tissues.

Prophylactic antibiosis was provided to prevent the influence of infection on our data. Per institutional recommendations, 3 days of prophylaxis were provided. Despite this, three wound infections occurred in the sandblasted group. The infection rate was not statistically greater than in the water-blasted group; however, our study was not powered to detect a threefold increase in infection rate between the two groups ( $80 \%$ power analysis revealed that 78 total animals would have been required to detect such a difference). The aim of our study was not to examine the role of infection on heterotopic bone formation. Despite two of the three infections progressing to rapid development of severe $\mathrm{HO}$, the infections did not statistically contribute to our ultimate conclusion that the media used did not influence the severity or type of ectopic bone formation.

Our study suggests that the mechanism of amputation is the most important predictor of ectopic bone formation in an amputation setting. The medium used did not influence the development of increased ectopic bone. Further study is warranted to elucidate the biomolecular pathophysiology of this disease process. The model can be used in future studies with reliable creation of ectopic bone using available blasting media. We anticipate that future investigations will elucidate similarities between service members' wartime extremity injuries and our animal model. We hope to identify various surgical and medical techniques to reduce heterotopic bone formation, potentially leading to beneficial therapeutic implications.

Acknowledgment We thank Dori Kelly MA, University of Maryland School of Medicine, Department of Orthopaedics (Baltimore, MD, USA), for professional manuscript editing and figure formatting.

\section{References}

1. Baldwin K, Hosalkar HS, Donegan DJ, Rendon N, Ramsey M, Keenan MA. Surgical resection of heterotopic bone about the elbow: an institutional experience with traumatic and neurologic etiologies. J Hand Surg Am. 2011;36:798-803.

2. Billings PC, Fiori JL, Bentwood JL, O'Connell MP, Jiao X, Nussbaum B, Caron RJ, Shore EM, Kaplan FS. Dysregulated BMP signaling and enhanced osteogenic differentiation of connective tissue progenitor cells from patients with fibrodysplasia ossificans progressiva (FOP). J Bone Miner Res. 2008;23:305313.

3. Brooker AF, Bowerman JW, Robinson RA, Riley LH Jr. Ectopic ossification following total hip replacement: incidence and a method of classification. J Bone Joint Surg Am. 1973;55:16291632.

4. Cipriano CA, Pill SG, Keenan MA. Heterotopic ossification following traumatic brain injury and spinal cord injury. $J \mathrm{Am}$ Acad Orthop Surg. 2009;17:689-697.

5. Covey DC. Blast and fragment injuries of the musculoskeletal system. J Bone Joint Surg Am. 2002;84:1221-1234.

6. Covey DC. Combat orthopaedics: a view from the trenches. J Am Acad Orthop Surg. 2006;14(10 spec no):S10-S17.

7. Forsberg JA, Pepek JM, Wagner S, Wilson K, Flint J, Andersen RC, Tadaki D, Gage FA, Stojadinovic A, Elster EA. Heterotopic ossification in high-energy wartime extremity injuries: prevalence and risk factors. J Bone Joint Surg Am. 2009;91:1084-1091.

8. Genêt F, Jourdan C, Schnitzler A, Lautridou C, Guillemot D, Judet T, Poiraudeau S, Denormandie P. Troublesome heterotopic ossification after central nervous system damage: a survey of 570 surgeries. PLoS One. 2011;6:e16632.

9. Hofmeister EP, Mazurek M, Ingari J. Injuries sustained to the upper extremity due to modern warfare and the evolution of care. J Hand Surg Am. 2007;32:1141-1147.

10. Jackson WM, Aragon AB, Bulken-Hoover JD, Nesti LJ, Tuan RS. Putative heterotopic ossification progenitor cells derived from traumatized muscle. J Orthop Res. 2009;27:1645-1651.

11. Kaplan FS, Glaser DL, Hebela N, Shore EM. Heterotopic ossification. J Am Acad Orthop Surg. 2004;12:116-125.

12. Leiste UH, Fourney WL, Duff T. Experimental studies to investigate pressure loading on target plates. Blasting and Fragmentation Journal. 2013;7:99-126.

13. Mavrogenis AF, Soucacos PN, Papagelopoulos PJ. Heterotopic ossification revisited. Orthopedics. 2011;34:177.

14. Michelsson JE, Granroth G, Andersson LC. Myositis ossificans following forcible manipulation of the leg: a rabbit model for the study of heterotopic bone formation. J Bone Joint Surg Am. 1980; 62:811-815.

15. Murray CK, Hsu JR, Solomkin JS, Keeling JJ, Andersen RC, Ficke JR, Calhoun JH. Prevention and management of infections associated with combat-related extremity injuries. J Trauma. 2008; 64(3 suppl):S239-251.

16. Owens BD, Kragh JF Jr, Macaitis J, Svoboda SJ, Wenke JC. Characterization of extremity wounds in Operation Iraqi Freedom and Operation Enduring Freedom. J Orthop Trauma. 2007;21: 254-257.

17. Pape HC, Marsh S, Morley JR, Krettek C, Giannoudis PV. Current concepts in the development of heterotopic ossification. $J$ Bone Joint Surg Br. 2004;86:783-787.

18. Potter BK, Burns TC, Lacap AP, Granville RR, Gajewski DA. Heterotopic ossification in the residual limbs of traumatic and combat-related amputees. J Am Acad Orthop Surg. 2006;14(10 spec no):S191-197.

19. Potter BK, Burns TC, Lacap AP, Granville RR, Gajewski DA. Heterotopic ossification following traumatic and combat-related 
amputations: prevalence, risk factors, and preliminary results of excision. J Bone Joint Surg Am. 2007;89:476-486.

20. Rumi MN, Deol GS, Bergandi JA, Singapuri KP, Pellegrini VD Jr. Optimal timing of preoperative radiation for prophylaxis against heterotopic ossification: a rabbit hip model. J Bone Joint Surg Am. 2005;87:366-373.

21. Rumi MN, Deol GS, Singapuri KP, Pellegrini VD Jr. The origin of osteoprogenitor cells responsible for heterotopic ossification following hip surgery: an animal model in the rabbit. J Orthop Res. 2005;23:34-40.

22. Schneider DJ, Moulton MJ, Singapuri K, Chinchilli V, Deol GS, Krenitsky G, Pellegrini VD Jr. The Frank Stinchfield Award: Inhibition of heterotopic ossification with radiation therapy in an animal model. Clin Orthop Relat Res. 1998;355:35-46.

23. Tannous O, Griffith C, O'Toole RV, Pellegrini VD Jr. Heterotopic ossification after extremity blast amputation in a
Sprague-Dawley rat animal model. J Orthop Trauma. 2011;25: 506-510.

24. Thomas BJ, Amstutz HC. Results of the administration of diphosphonate for the prevention of heterotopic ossification after total hip arthroplasty. J Bone Joint Surg Am. 1985;67:400403.

25. Vasileiadis GI, Sakellariou VI, Kelekis A, Galanos A, Soucacos PN, Papagelopoulos PJ, Babis GC. Prevention of heterotopic ossification in cases of hypertrophic osteoarthritis submitted to total hip arthroplasty: etidronate or indomethacin? J Musculoskelet Neuronal Interact. 2010;10:159-165.

26. Walton M, Rothwell AG. Reactions of thigh tissues of sheep to blunt trauma. Clin Orthop Relat Res. 1983;176:273-281.

27. Zaccalini PS, Urist MR. Traumatic periosteal proliferations in rabbits: the enigma of experimental myositis ossificans traumatica. J Trauma. 1964;4:344-357. 